\title{
Application of a fast and efficient algorithm to assess landslide-prone areas in sensitive clays in Sweden
}

\author{
C. Melchiorre and A. Tryggvason \\ Department of Earth Science, Uppsala University, Villavägen 16, 75236 Uppsala, Sweden \\ Correspondence to: A. Tryggvason (ari.tryggvason@geo.uu.se)
}

Received: 7 November 2014 - Published in Nat. Hazards Earth Syst. Sci. Discuss.: 19 December 2014

Revised: 4 September 2015 - Accepted: 11 October 2015 - Published: 21 December 2015

\begin{abstract}
We refine and test an algorithm for landslide susceptibility assessment in areas with sensitive clays. The algorithm uses soil data and digital elevation models to identify areas which may be prone to landslides and has been applied in Sweden for several years. The algorithm is very computationally efficient and includes an intelligent filtering procedure for identifying and removing small-scale artifacts in the hazard maps produced. Where information on bedrock depth is available, this can be included in the analysis, as can information on several soil-type-based cross-sectional angle thresholds for slip. We evaluate how processing choices such as of filtering parameters, local cross-sectional angle thresholds, and inclusion of bedrock depth information affect model performance. The specific cross-sectional angle thresholds used were derived by analyzing the relationship between landslide scarps and the quick-clay susceptibility index (QCSI). We tested the algorithm in the Göta River valley. Several different verification measures were used to compare results with observed landslides and thereby identify the optimal algorithm parameters. Our results show that even though a relationship between the cross-sectional angle threshold and the QCSI could be established, no significant improvement of the overall modeling performance could be achieved by using these geographically specific, soil-based thresholds. Our results indicate that lowering the cross-sectional angle threshold from $1: 10$ (the general value used in Sweden) to $1: 13$ improves results slightly. We also show that an application of the automatic filtering procedure that removes areas initially classified as prone to landslides not only removes artifacts and makes the maps visually more appealing, but it also improves the model performance.
\end{abstract}

\section{Introduction}

Landslides in sensitive clays are a recognized natural hazard in Canada, Norway, and Sweden. As they may occur in very gentle slopes which may be incorrectly presumed to be stable, they are a threat to human lives as well as for transportation corridors (e.g., Larsson et al., 2008), for example. Signs of creep have on some occasions been documented prior to landslides in sensitive clays (e.g., Demers et al., 1999), but often no signs of deformation and displacement are observed before the actual failure. Therefore landslide hazard or susceptibility maps are essential tools to minimize their impact. In Sweden sensitive clays are classified as quick clays if the sensitivity (defined as the ratio between the shear strength during undrained conditions and its remoulded shear strength) is at least 50 or higher and the fully remoulded shear strength is below $0.4 \mathrm{kPa}$ (Osterman, 1963; Karlsson and Hansbo, 1989).

During the last two decades many scientific studies regarding landslide susceptibility assessment have been published, with great focus on the use of statistical and datadriven methods (e.g., Guzzetti at al., 2006, and references therein). However, relatively few of these deal with statistical assessment of landslide hazard in sensitive clays (Erener et al., 2007; LESSLOSS, 2007; Quinn, 2009). Erener et al. (2007) analyzed mainly governing factors from topography (e.g., slope angle and curvature) derived from a digital elevation model (DEM), whereas Quinn (2009) also included soil type, soil thickness, bedrock type and land use. Increased interest in mapping landslide susceptibility in Sweden led the Geological Survey of Sweden (SGU) to initiate a project on the matter by implementing the first step of a methodology to derive high-resolution stability maps (Berggren et al., 1991; Lundström and Andersson, 2008). Similar efforts have also 
been made in Austria, Norway, and Italy (Bell at al., 2013; Høst et al., 2013; Trigila et al., 2013).

In Sweden, Norway and Canada the methods to map landslide hazard in sensitive clays have traditionally used criteria mainly based on geology (e.g., over-consolidation ratio, sensitivity, thickness of the sensitive clay layer), topography (e.g., height of the slope), the presence of earlier events, and erosion (Lundström and Andersson, 2008). In Sweden, the methodology used to derive such maps includes a first step which aims at recognizing the soil and slope conditions influencing landslide occurrence (Berggren et al., 1991; Lundström and Andersson, 2008). A typical area where landslides in sensitive clays occur is characterized by a relatively steep slope close to a river or ravine above which there is relatively flat terrain where significant mass movements may also occur. The surface slope angle is therefore not representative of the conditions in which landslides in sensitive clays occur. Berggren et al. (1991) suggested instead that areas could be classified as susceptible to landslides in sensitive clays based on the ratio $\mathrm{dH} / \mathrm{dL}$ (the cross-sectional angle), where $\mathrm{dH}$ is the difference in height between the surface point examined and any neighboring point, and $\mathrm{dL}$ is the corresponding horizontal distance (i.e., potential retrogression distance). In our algorithm, if the "cross-sectional angle" defined by $\mathrm{dH} / \mathrm{dL}$ is below a given (empirically selected) threshold, the given area can be regarded as "stable". Berggren et al. (1991) found that all landslides in their study occurred at steeper slopes than $1: 10$; thus this was suggested as a threshold value. Whereas the calculation of the cross-sectional angle is simple in one dimension, it is not trivial in two dimensions as movements may not be confined to a single direction due to, for example, the presence of stable material.

In this contribution, we test our algorithm, which is able to quickly and efficiently assess landslide hazard based on topography and information on soil type and slope structure. The algorithm uses a local visibility operator to calculate the cross-sectional angle: it checks the elevation of the surrounding cells and assigns to them a value given by the crosssectional threshold (Tryggvason et al., 2015). This procedure is repeated until no further change in elevation is observed. This computational solution allows fast processing times and the use of additional localized information on soil depth and cross-sectional angle thresholds. Moreover, the algorithm includes a filtering procedure designed to remove areas not prone to landslides: working with real data, especially highresolution data, there will be numerous areas that violate the cross-sectional threshold due to errors in topographic (altitude) data or "irrelevant" small-scale topographic features such as trenches and ditches. Such features most likely do not constitute any real landslide hazard and should rather be removed by a quick and efficient (preferably automated) procedure (Lindberg et al., 2011). Our algorithm thus combines a number of types of data and logical assessment to provide a powerful first-step tool to use in a national program aimed at mapping susceptibility of landslides in sensitive clays. We have chosen the Göta River valley as a test site to evaluate the performance of the algorithm on real data. We compared results obtained with and without including a depth to bedrock map as input data. We also compared results produced using different cross-sectional thresholds to areas where landslides are known to occur, in order to evaluate the suitability of the threshold value of $1: 10$ suggested by Berggren et al. (1991) and widely used in Sweden today.

Specifically, we aim at (1) analyzing the impact of the filtering procedure on the performance of the maps, (2) investigating whether using available information on the depth to bedrock improves results, (3) examining whether different morphological parameters are related to the presence of sensitive clays and may support a particular cross-sectional angle threshold, and finally (4) giving advice on how to use the algorithm and what data to use in the national program for landslide susceptibility assessment.

\section{Study area and data description}

The Göta River valley is located in the southwestern part of Sweden, connecting Lake Vänern in the north with the Kattegat Sea at the city of Gothenburg in the south. Compared to many other areas in Sweden, the Göta River valley has a high frequency of landslides (Hågeryd et al., 2007) caused by the presence of quick clays.

In southwestern Sweden the last deglaciation started approximately 14500 years $\mathrm{BP}$ and lasted for at least 5000 years producing a series of ice-marginal positions (Lundqvist and Wohlfarth, 2001). During this period deposition of glaciomarine sediments occurred in areas below sea level. Holocene transgression has been documented at about $10000 \mathrm{BP}$ (Svedhage, 1985) and between 9000 and 7000 BP (Påsse, 1983). The clay sequences deposited during the last deglaciation are typically found above either bedrock or relatively thin diamicton and sand. The clays can be laminated and interbedded with fine-sand layers in their lowermost portions, and the clay-bedrock or clay-sediment contact is abrupt (Stevens, 1990).

In the Göta River valley the deposition of clay sediments began $12000 \mathrm{BP}$ in salt water when the relative sea level was $125 \mathrm{~m}$ above present level. Glaciomarine sediments contain different silt content and laminae in the sediment sequences which represent several depositional environments (Stevens, 1990). Coarse material lenses are also common in the sediment sequences due to periods of ice re-advancement, marine transgression and fluvial transportation.

During and after land uplift, the clay sediments deposited in salt water but now above sea level underwent leaching by fresh water. Leaching is one factor influencing quick clay formation (Torrance, 1983, 2014; Andersson-Sköld et al., 2005), and it has been recognized as the key factor in quick clay formation in the Göta River valley (Rankka et al., 2004). Quick clays are common in the whole valley and 


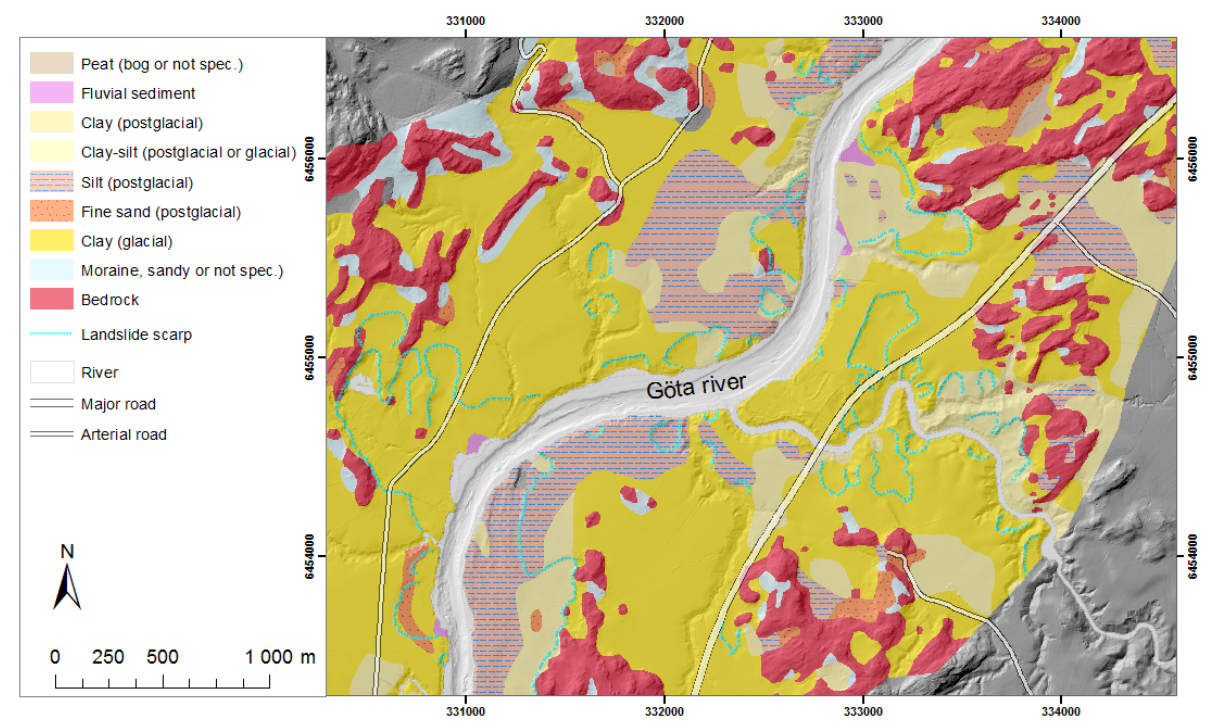

Figure 1. Landslide scarp map and Quaternary deposit map at $1: 50000$ for a subregion of the Göta Älv valley.

they reach a higher spatial frequency north of Lilla Edet (AA.VV., 2012), where the majority of landslides are localized. The narrow northern part of the valley is predominantly covered by glacial fine clay while the central part by postglacial silt and glacial/post-glacial clay (Fig. 1). In the southern part of the valley glacial clay sediments are confined to the valley sides in the proximity of the bedrock outcrops, whereas post-glacial clay sediments cover the main part of the valley floor.

\section{Methodology}

\subsection{Description of the algorithm and of the post-processing filtering}

The first computer implementation adopted in Sweden to produce landslide susceptibility maps by identifying areas above a specified cross-sectional angle used the visibility operator of ArcGIS (ESRI, Redlands, CA). The visibility operator is able to detect areas above a given altitude angle (our cross-sectional angle threshold). Our algorithm is instead based on a locally limited operator that is applied iteratively. Rather than searching for surrounding cells above a given altitude angle, the operator checks whether the central cell rises above the given cross-sectional angle to any of the surrounding cells (the eight closest cells are examined). If the cell is above neighboring cells and contains potentially unstable soil it is, for the calculations, reassigned a topographic height corresponding to the critical elevation. The procedure is iterated until a global solution (i.e., stable solution) is reached. This iterative scheme allows the use of several cross-sectional angle thresholds (hypothetically, one for each soil type) and (sparse) information on depth to bedrock, something that is not as straightforward to implement in the classical visibility approach. The bedrock topography may act as a barrier, blocking line of sight, and thus reducing the area affected by a possible landslide (Tryggvason et al., 2015). Specifically, the steps executed in the algorithm are the following: the algorithm checks whether a cell is within soils that can be affected by landslides; if it is, the algorithm checks whether the cross-sectional angle calculated between the cell and its surrounding cells is steeper than the cross-sectional angle threshold; if it is, the elevation of the cell is lowered until the cross-sectional angle calculated between the cell and its surrounding cells equals the cross-sectional angle threshold. If the bedrock surface is reached, the elevation is lowered no further. The final solution is reached when no further change in elevation occurs (Tryggvason et al., 2015).

The raw output of the algorithm, especially when a highresolution DEM is used, shows areas marked as prone to landslides which clearly should not be marked as such - either because they are too small or because they are anthropogenic features (e.g., ditches). A filtering procedure was therefore introduced in order to automatically remove these areas. Areas are removed as potential landslide sites if they are smaller than a defined areal threshold or if the difference between the highest and the lowest point within the area is below a defined elevation threshold. In some cases, a patchwork of smaller areas that would normally be filtered out may be wrongly perceived as a single large area of potential slip due to a network of connecting corridors (e.g., ditches or artifacts in the data). To avoid this a pre-filter is applied that removes all "thin" areas. The width of the corridors is defined by the pre-filter parameter and is referred to as "neck size". Typically a neck size of a few samples (1-7) is sufficient to successfully separate the individual potential landslides. 
Once the algorithm results are pre-filtered the two other filtering criteria can be successfully applied.

\subsection{Data description}

We used the following map data in our analysis: DEM, soil deposits, depth to bedrock, quick-clay susceptibility index (QCSI), landslide scarps and probability of landslides. The DEM, soil deposit and depth to bedrock maps were used as the input raster data for the algorithm; the QCSI and landslide scarp maps were used to derive QCSI-dependent crosssectional angle thresholds; the landslide scarp and the probability of landslide maps were used to assess the performance of the model.

The QCSI represents the probability of finding quick clay in a specific area (Persson et al., 2014). In the work of Persson et al. (2014), the QCSI was assessed by a multi-criteria evaluation. Several factors influencing quick clay formation were taken into account: stratigraphy, potential for groundwater flux, relative infiltration capacity, and geomorphological conditions for high groundwater flux. The resolution of the QCSI map is $50 \mathrm{~m}$.

We used the NNH (Swedish acronym for "New National Elevation model") data (Lysell, 2013) as DEM. The NNH data are produced from elevation measurements acquired by airborne laser scanners and are supplied at $2 \mathrm{~m} \times 2 \mathrm{~m}$ grid resolution.

The soil information was extracted from the soil layer database of the Swedish Geological Survey (SGU), which contains data on soil genesis and grain size. The map is at $1: 50000$ scale and it is provided in vector format.

The depth to bedrock map is a product of SGU (Daniels and Thunholm, 2014) which is generated by analyzing and interpolating soil depth data from three different SGU databases: (1) soil depth (depth to bedrock) data from boreholes and wells that reached the bedrock surface, (2) soil depth data from boreholes and wells that did not reach the bedrock surface, thus showing minimum assessed soil thinness, and (3) soil depth data for areas with little or no soil cover, extracted from several other databases that contain points indicating no soil or very thin soil (e.g., bedrock outcrop, ice striation). Our final depth to bedrock map was generated by interpolating to a $50 \mathrm{~m}$ uniform grid using the inverse weight distance method (Daniels and Thunholm, 2014). Where there is no information, the depth is assumed large; thus it will not influence the results in our modeling.

The landslide scarp map is a product of SGU and it is derived by image interpretation of the NNH data on screen (SGU, 2014). It was converted from a vector map to a raster matching the resolution of the DEM used.

The landslide probability map is a product of SGI - the Swedish Geotechnical Institute (AA.VV., 2012). The map was produced by calculating the factor of safety along several sections and through a stochastic analysis of the stability calculation's governing variables (Berggren et al., 2011). The landslide probability map shows the probability of landslide divided into five classes: negligible probability, low probability, some probability, pronounced probability, and obvious probability (AA.VV., 2012). As the time-dependent factors (e.g., changes in groundwater level and pore pressure) only slightly influenced the computation of the landslide probability in the Göta Älv area, we argue that it is meaningful to compare the results of our algorithm to the SGI landslide probability map.

\subsection{Cross-sectional angle thresholds}

Retrogression distance of landslides in sensitive clays depends upon topography and soil properties: the crosssectional angle is related to the geotechnical properties of the clays, specifically clay sensitivity (Mitchell and Markell, 1974; AA.VV., 2012). Since collecting large quantities of detailed geotechnical data is prohibitively expensive, we derive relationships between observed cross-sectional angles and geotechnical parameters of the observed slope. It has been shown that the QCSI values calculated in southwestern Sweden are correlated with the sensitivity of the clay (Persson at al., 2014); we therefore used the QCSI as a proxy for the clay sensitivity. The cross-sectional angles were computed from the landslide scarp map for a subset of identified landslide scarps. Each cross-sectional angle was compared to the maximum QCSI value for soil within the specific scarp area by plotting angle against maximum QCSI and taking the maximum angle value within 13 discrete QCSI bins.

\subsection{Model evaluation methodology}

One way to evaluate the performance of a landslide susceptibility map is to compare it to, for example, a landslide inventory map (i.e., observed data) - if it exists. Two statistical measurements may be used, namely "sensitivity" (not to be confused with clay sensitivity or the sensitivity maps described above) and "specificity" (e.g., Oh and Pradhan, 2014). The sensitivity is the ratio between the number of correctly classified positive samples (i.e., true positive) and the total number of positive samples (i.e., cells where landslides have occurred), whereas the specificity is the ratio between the number of correctly classified negative samples (i.e., true negative, areas where no landslide has occurred) and the total number of negative cells on our hazard map. See Table 1 for details on the computations. These statistics may be misleading for some areas partly because slopes which are inherently unstable may not yet have developed slip. In the case of frequent and small landslide events, this is less of a problem, whereas in the case of infrequent and relatively big events this approach is not feasible. This is because of the high likelihood that the landslide has yet to occur, and unstable areas will be wrongly assumed to be stable. In order to overcome this problem and to obtain reasonable estimations of model 
performance, we used two maps to validate the models: the landslide scarp map and the probability of landslides map.

The degree of agreement between the model results and the observed landslide scarps was evaluated using threshold-based sensitivity curves and prediction rate curves. Threshold-based sensitivity curves show the model's ability to correctly classify landslides if each individual landslide is considered as one sample. We consider contiguous (potential landslide) areas (scarps) on our hazard map. If a slide has been documented in this area and if over a given proportion (e.g., $50 \%$ ) of the cells on our map within this area are positive, the analysis is classed as correct. The thresholdbased sensitivity curves show the sensitivity (i.e., percentage of correctly classified landslide scarps) versus the sensitivity threshold (i.e., percentage of cells correctly classified in each single scarp). The higher the sensitivity at each sensitivity threshold, the higher the model performance. Prediction rate curves show the sensitivity versus the percentage of area classified as prone to landslides. Because the analysis is performed on raster data, the sensitivity of the prediction rate curve is computed as the ratio between the number of cells correctly classified and the total number of cells with observed landslides. Each single cell is therefore considered as one sample regardless of which landslide it belongs to. The aim of the prediction rate curves, as introduced by Chung and Fabbri (2003), is to assess the performance of the entire susceptibility map. The assumption behind the prediction rate curves is that the higher the number of correctly classified landslides and the lower the area classified as susceptible to landslides, the better the performance. The susceptibility is often represented by a continuous range (e.g., $[0,1])$. The prediction rate curves are computed by first sorting the susceptibility level in descending order and then dividing by the total number of pixels of the study area. The obtained values range from 0 to 1 and represent the portion of the study area classified as susceptible. Those values are finally put in bins with intervals of equal size and the percentage of landslides is computed in each bin. Since our algorithm has a dichotomous output (i.e., not prone, prone to landslides), it is not possible to calculate the prediction rate curve for each single map; therefore we used the concept of the prediction rate curve to evaluate the performance of a set of maps (e.g., filtered maps). We computed the prediction rate curves by plotting the sensitivity data and total area classified as unstable data from several maps in one graph. This means that one single point of the prediction rate curve represents the performance of one map.

The second type of validation was executed by comparing the model results with the probability of landslide map. The original five classes of the probability of landslide map were condensed into two classes: stable (negligible probability and low probability classes) and unstable (some probability, pronounced probability, and obvious probability). The Gilbert skill score (Gilbert, 1884; Schaefer, 1990) and the Heidke skill score (Heidke, 1926) were computed for each map. The
Table 1. Performance statistics. tp: true positives, tn: true negatives, fp: false positives, fn: false negatives. $T$ equals total number of forecasts, and $E$ equals the expected number of correctly classified samples due to random chance.

\begin{tabular}{ll}
\hline Sensitivity & $\frac{\mathrm{tp}}{\mathrm{tp}+\mathrm{fn}}$ \\
\hline Specificity & $\frac{\mathrm{tn}}{\mathrm{fp}+\mathrm{tn}}$ \\
\hline Heidke skill & $\frac{\mathrm{tp}+\mathrm{tn}-E}{T-E}$, \\
score & where \\
& $E=\frac{1}{T}[(\mathrm{tp}+\mathrm{fn})(\mathrm{tp}+\mathrm{fp})+(\mathrm{tn}+\mathrm{fn})(\mathrm{tn}+\mathrm{fp})]$ \\
& and $T=\mathrm{tp}+\mathrm{tn}+\mathrm{fp}+\mathrm{fn}$ \\
\hline \multirow{2}{*}{ Gilbert skill } & $\frac{\mathrm{tp}-\mathrm{tp} \text { pandom }}{\mathrm{tp}+\mathrm{fn}+\mathrm{fp}-\mathrm{tp} \text { random }}$, \\
score & where \\
& $\mathrm{tp}_{\text {random }}=\frac{(\mathrm{tp}+\mathrm{fn})(\mathrm{tp}+\mathrm{fp})}{T}$ \\
\hline
\end{tabular}

Gilbert skill score measures correctly classified positive samples after removing true positives due to random chance (implying that a compensation is made for the number of used samples and the number of not correctly classified samples, see Table 1). The Heidke skill score measures correctly predicted samples (both positive and negative) after removing samples which are correctly classified due to random chance (see Table 1 for the details).

\section{Analysis and results}

\subsection{Relationship between cross-sectional angle and QCSI}

In order to perform the analysis the QCSI map was interpolated from a $50 \mathrm{~m} \times 50 \mathrm{~m}$ pixel resolution to a $2 \mathrm{~m} \times 2 \mathrm{~m}$ pixel resolution and the landslide scarp map was converted from vector to raster form. Cross-sectional angle values $(\mathrm{dH} / \mathrm{dL})$ for each individual, separate scarp on SGU's scarp map were compared to the QCSI values for that scarp. The $\mathrm{dH}$ value represents the estimated height of the slope before the landslide event, and $\mathrm{dL}$ represents the maximum retrogression distance for the scarp. As exact information on topography prior to the slide is not available in our input data, for our comparison we manually selected a subset of 71 scarps and estimated $\mathrm{dH}$ from areas to the side of the slide which were judged to be representative. For each scarp the maximum value of QCSI was extracted from the area of the defined scarp. The reason the maximum was chosen, and not some sort of mean, is simply the assumption that the point (or area) with highest QCSI (the weakest material) is likely to represent the starting point of the landslide - or at least an area strongly influencing the development of the landslide. The relationship between the maximum QCSI value and the cross-sectional angle in Fig. 2 was then analyzed. Even if a simple linear relationship between the cross-sectional angle and the QCSI cannot be extracted from Fig. 2, we could still 


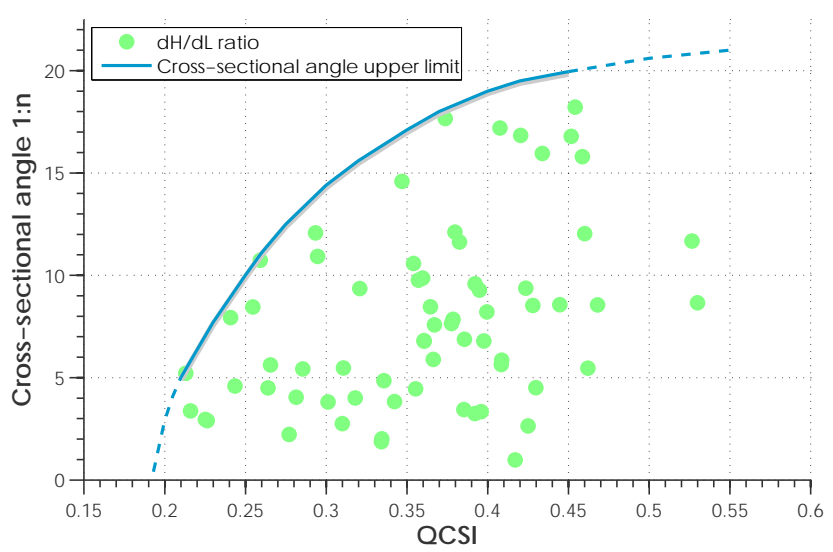

Figure 2. Relationship between the QCSI and the cross-sectional angle computed from a subsample of the landslide scarp data.

identify an upper limit of the cross-sectional angle for a given QCSI. A similar relationship was found by comparing the cross-sectional angle values with the sensitivity of the clays (AA.VV., 2012), supporting that our approach is reasonable.

\subsection{Input data and filter parameters}

The DEM was used without further processing, whereas the depth to bedrock map was resampled to $2 \mathrm{~m}$ pixel size. We converted the soil map to binary form according to an SGU's assessed likelihood that the soil type at each position contains sensitive clay (see Table 2). Soils considered potentially unstable include clay and silt deposits of glacial or post-glacial origin. We refer to this as re-classed to produce a "best-case soil class" map, as other areas are presumed not to include any quick clay. The results were interpolated onto a $2 \mathrm{~m} \times 2 \mathrm{~m}$ grid. SGU's soil map was also used to produce a map containing combined QCSI and cross-sectional angle information for each positive cell on the best-case soil class map. This (QCSI-dependent) map was produced by using 13 subclasses (Table 3) according to the relationship between the cross-sectional angle and the QCSI shown in Fig. 2. For example, Class 1 was assigned to pixels with QCSI lower than 0.195 , Class 2 to cells with QCSI between 0.195 and 0.2, and so on.

In order to identify the optimal filter parameters we selected a test area and executed multiple trial runs of the prefilter varying the neck size threshold and the parameters describing the minimal area necessary for a landslide to occur and the elevation difference criteria. The tests were carried out using the best-case scenario soil class map, with the cross-sectional angle thresholds set to $1: 10$ (Berggren et al., 1991). Because the neck size is a parameter of the pre-filter aimed at separating different landslide areas, adjustments in the neck size were never tested alone but in combination with one of the other two filters.
Table 2. Soil deposits considered unstable (1) in the best-case scenario.

\begin{tabular}{lc}
\hline & Best case \\
\hline Peat (bog) & 0 \\
Peat (bog or not specified) & 0 \\
Fluvial sediments & 0 \\
Fluvial sediments (sand) & 0 \\
Clay (postglacial) & 1 \\
Clay-silt (postglacial or glacial) & 1 \\
Silt (post-glacial) & 1 \\
Fine sand (postglacial) & 0 \\
Sand (postglacial or not specified) & 0 \\
Gravel (postglacial or not specified) & 0 \\
Clay (glacial) & 1 \\
Silt (glacial) & 1 \\
Glaciofluvial sediment, sand block & 0 \\
Glaciofluvial sediment, sand & 0 \\
Moraine, sandy or not specified & 0 \\
\hline
\end{tabular}

Table 3. Upper limits of the QCSI used to divide the best-case soil class in 13 subclasses and the assigned cross-sectional angle thresholds.

\begin{tabular}{llc}
\hline & QCSI upper limit & Angle \\
\hline Class 1 & 0.195 & None \\
Class 2 & 0.2 & $1: 1$ \\
Class 3 & 0.21 & $1: 3$ \\
Class 4 & 0.23 & $1: 5$ \\
Class 5 & 0.25 & $1: 8$ \\
Class 6 & 0.3 & $1: 10$ \\
Class 7 & 0.32 & $1: 13$ \\
Class 8 & 0.35 & $1: 15$ \\
Class 9 & 0.4 & $1: 17$ \\
Class 10 & 0.45 & $1: 19$ \\
Class 11 & 0.5 & $1: 20$ \\
Class 12 & 0.55 & $1: 21$ \\
Class 13 & 1 & $1: 22$ \\
\hline
\end{tabular}

The model performance with different filter parameters was assessed by similarity with SGU's landslide scarp map using the Gilbert skill score, the Heidke skill score, and the prediction rate curves, i.e., sensitivity versus the total area assessed to be prone to landslides (see Fig. 3). The Heidke skill score shows model performance estimate continuously increases if the neck size increases, and reaches a maximum when the elevation difference threshold is equal to $5 \mathrm{~m}$ (Fig. 3). The minimal area threshold does not have any influence on the performance (Fig. 3b). The Gilbert skill score (not shown) gave almost identical results as the Heidke skill score. Figure 4 shows that the higher the elevation threshold the higher the performance in the sense that the sensitivity remains stable while the percentage of area assessed to be prone to landslides decreases. After taking the results in Figs. 3 and 4 into consideration we decided to continue 


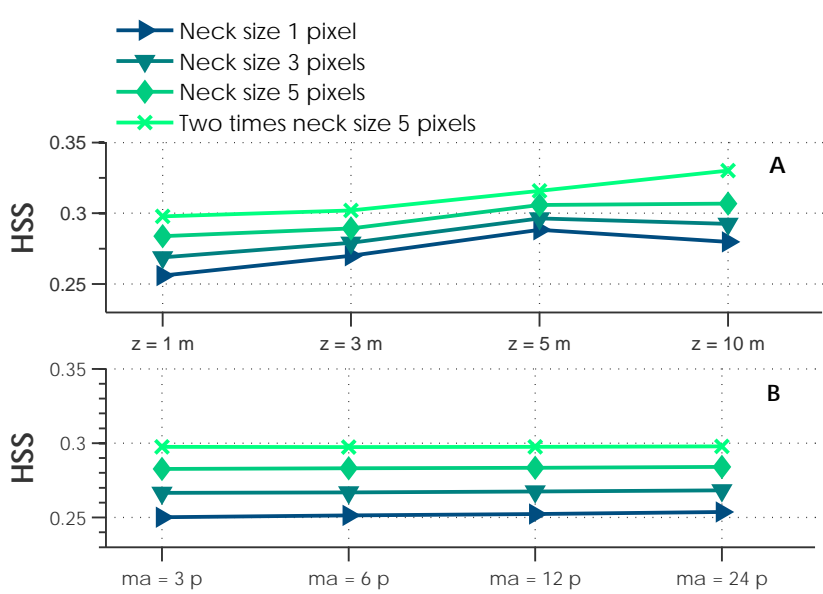

Figure 3. Heidke skill scores obtained by varying the elevation difference criterion (a), and the minimum area criterion (b). Results are shown for four pre-filtering options (i.e., neck size). The elevation difference criterion is given in meters $(\mathrm{m})$, whereas the minimum area criterion in number of pixels $(p)$.

the analysis applying the pre-filter with the neck size equal to 5 pixels and setting the elevation difference filter parameter equal to $5 \mathrm{~m}$. Small areas were filtered out by setting the minimal area threshold equal to 6 pixels (i.e., $24 \mathrm{~m}^{2}$ ). Figure 5 shows the effect of the filtering procedure using the optimized parameters in a subarea of the study area.

\subsection{Effects of depth to bedrock and filter}

In order to study the effect of the inclusion of depth to bedrock information with and without the filtering described in the previous section, test runs each with a fixed crosssectional angle threshold were used to analyze the best-case scenario class map. We calculated threshold-based sensitivity curves for each cross-sectional angle threshold in Table 3, but we show only the results for the ratio $\mathrm{dH} / \mathrm{dL}$ equal to $1: 8$ and $1: 22$ (Fig. 6). The curve calculated for the ratio $1: 8$ shows that the performance of the model deteriorated when the filter was applied (Fig. 6a), since the curve of the filtered maps lies below the curve of the unfiltered maps. This was especially evident for thresholds between 40 and $80 \%$. This result is expected as the curves only show the correctly classified landslides and provide no information regarding whether the classification of the stable areas has been improved or not. However, there is no difference between filtered and unfiltered maps if the cross-sectional angle is $1: 22$ as shown in Fig. 6b. When taking the total area assessed to be prone to landslides into consideration, as shown in the prediction rate curves of Fig. 7, the performance is apparently better when the filtering is used. For cross-sectional angle thresholds between $1: 8$ and $1: 13$, the filtered maps outperform the maps that have not been filtered. The values of sensitivity are approximately the same, whereas the total area classified as prone to landslides is significantly lower for the

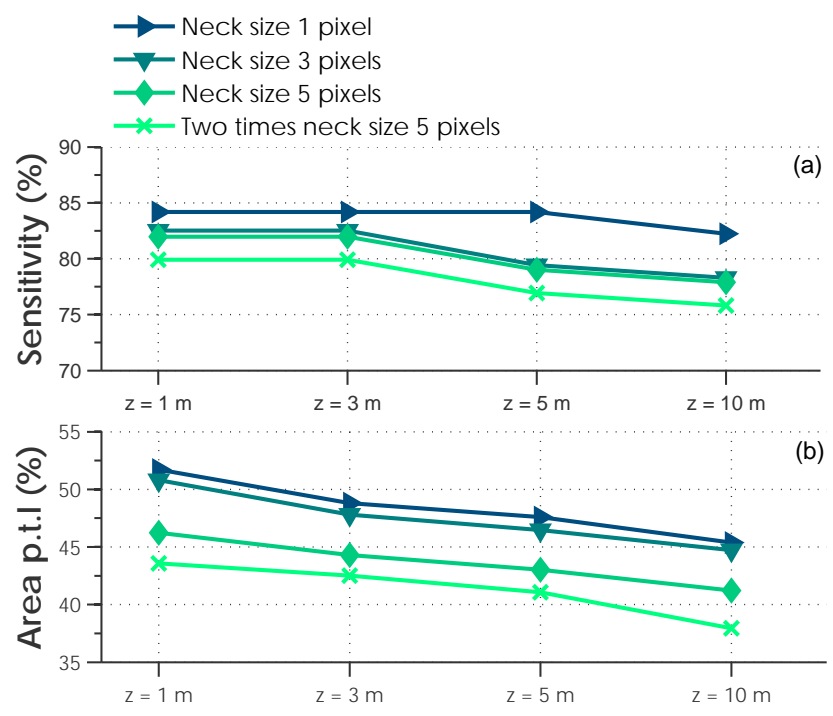

Figure 4. The sensitivity (a) and area prone to landslides (b) obtained by varying the elevation difference criterion. Results are shown for four pre-filtering options (i.e., neck size). The elevation difference criterion is given in meters $(\mathrm{m})$.

filtered maps. The use of the bedrock information does not significantly increase the performance of the filtered maps. The Gilbert skill score and the Heidke skill score (Fig. 8) show higher values (i.e., better model performance) for filtered than for unfiltered maps. The difference in performance between the unfiltered and the filtered maps is clear for low cross-sectional angle thresholds, whereas at high crosssectional angle thresholds the performances are very similar. Similar conclusions can be drawn when comparing the maps obtained by with or without the depth to bedrock information. While the use of depth to bedrock information increases the value of the statistical measurements, its inclusion provides a relatively small improvement to model performance when compared to the effects of using the filtering. Worth noticing is that the improvement in model performance is only evident at low values of the cross-sectional angle thresholds for all cases considered. In general, all four sets of maps (i.e., no bedrock/no filter, no bedrock/filter, bedrock/no filter, bedrock/filter) show similar trends in the Gilbert skill score and the Heidke skill score when the cross-sectional angle threshold is decreased: the scores reach their maximum at ratio $1: 10$ and $1: 13$ respectively and remain stable even if the thresholds are further decreased. From this we conclude that the inclusion of the filtering procedure has a more significant effect on improving model performance compared to the addition of the depth to bedrock information.

\subsection{Effects of cross-sectional angle thresholds}

To assess whether the QCSI-dependent cross-sectional angle thresholds would influence model performance, simulations were carried out for each cross-sectional angle threshold in 


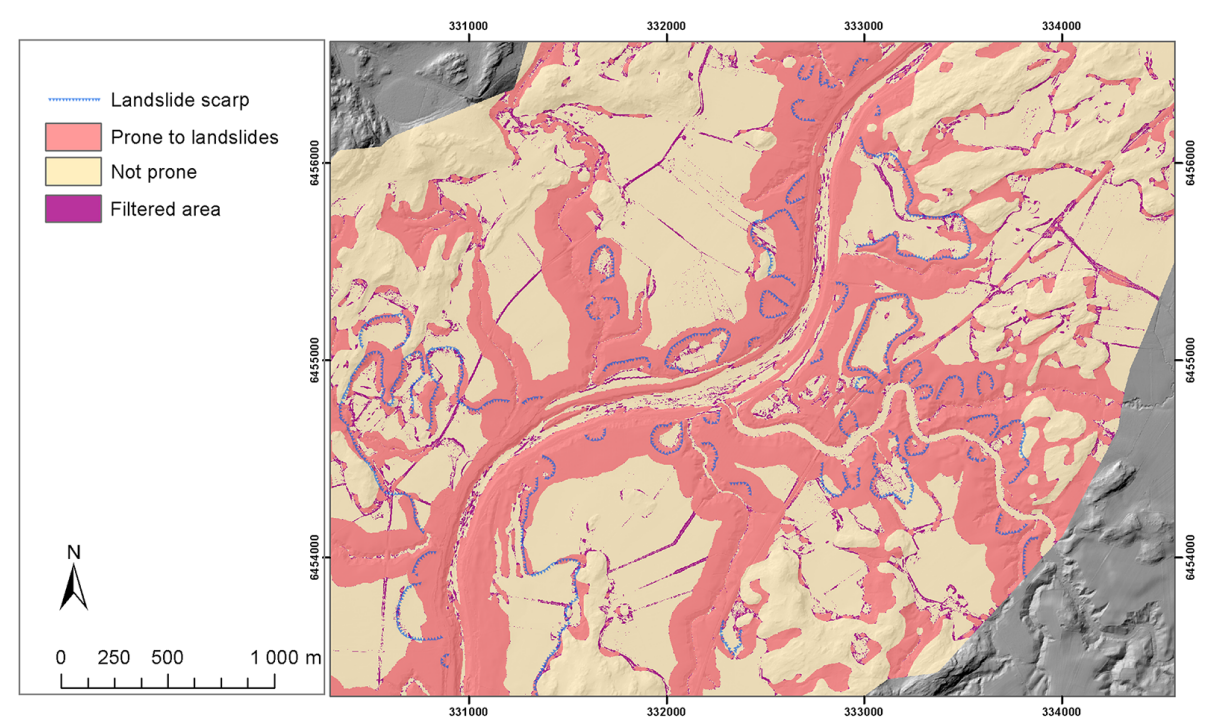

Figure 5. Map of area prone to landslides obtained using $1: 10$ as cross-sectional angle thresholds for the best-case scenario soil class. The filtered areas were removed by using the following filtering parameters: double pre-filtering with 5-pixel neck size, elevation difference equal to $5 \mathrm{~m}$, and minimal area threshold equal to 6 pixels.

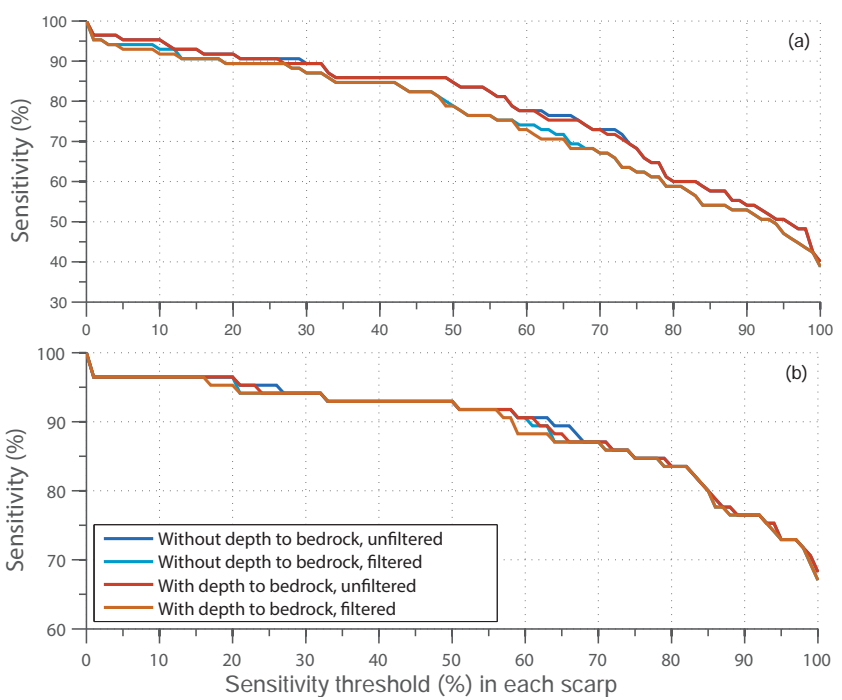

Figure 6. Threshold-based sensitivity curves showing the effect of the depth to bedrock data and the filtering procedure on the areas prone to landslides with cross-sectional angle threshold equal to 1 : 8 (a) and equal to $1: 22$ (b).

Table 3. Every simulation was done using two cross-sectional angle thresholds to assess whether the added information would improve results compared to when only one threshold was used. For example, for Class 7 all cells from Class 2 to 6 were assigned the cross-sectional angle threshold $1: 10$, and for all cells from Class 7 to 13 the threshold $1: 13$ was used. This simulation was compared to the simulation with all cells from Class 2 to 13 given the cross-sectional angle threshold $1: 13$. Consequently, the former simulation will identify less

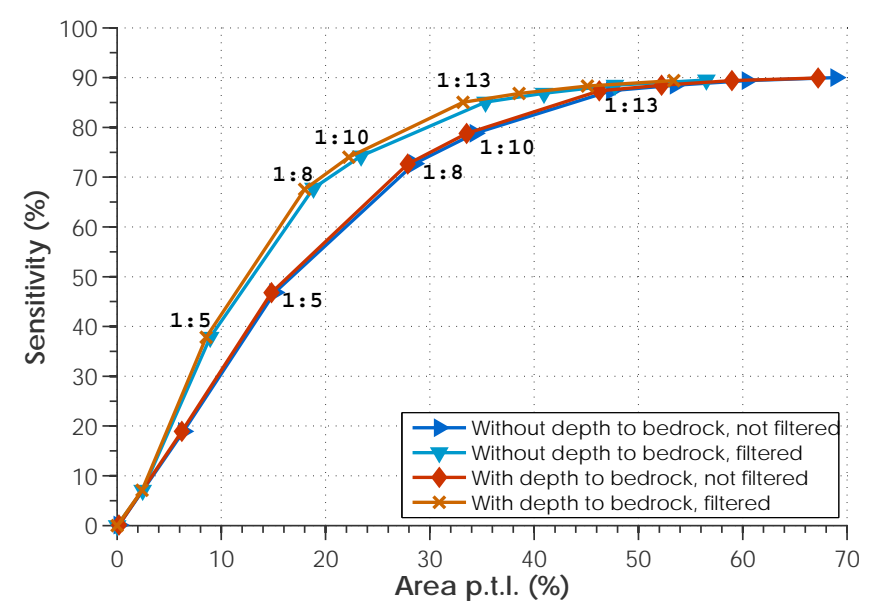

Figure 7. Prediction rate curves showing the effect of the depth to bedrock data and the filtering procedure on the areas prone to landslides. The cross-sectional angle threshold varies from $1: 1$ to $1: 22$. The values of the cross-sectional angle thresholds are shown for some points along the prediction rate curves.

area as prone to landslides as a higher cross-sectional angle is tolerated for part of the area than in the latter. This is seen in Fig. 9, where the curve denoted QCSI $1: 13$ is consequently below the best-case $1: 13$ curve as fewer slides are identified. However, if also fewer "false positives" are generated, indicating that the QCSI information has provided significant information on which areas to "clear", the Heidke and Gilbert skill scores could be expected to be higher for this simulation. As seen in Fig. 10, this is not the case - the curve for the QCSI-dependent cross-sectional angle threshold is con- 

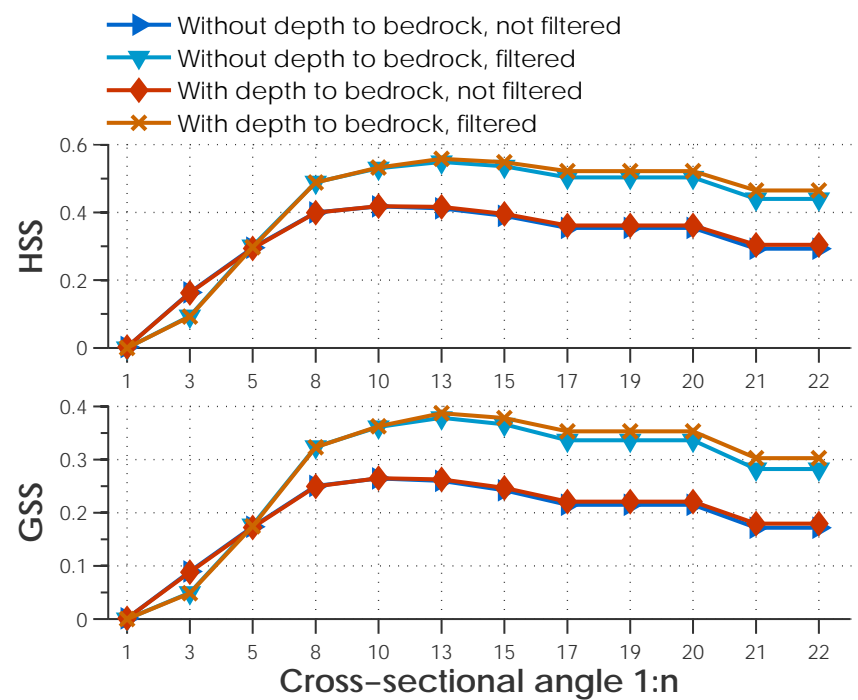

Figure 8. Heidke skill score and Gilbert skill score of the areas prone to landslides obtained with or without the depth to bedrock data and with or without filtering. The effect of the depth to bedrock data and the filtering is shown for several values of the crosssectional angle threshold (i.e., from $1: 1$ to $1: 22$ ).

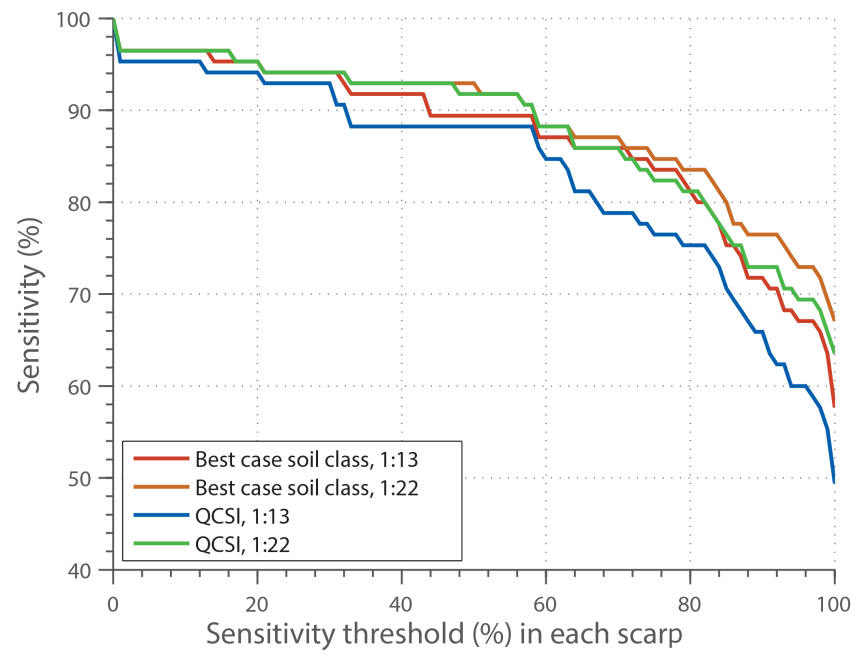

Figure 9. Threshold-based sensitivity curves of the areas prone to landslide obtained with cross-sectional angle thresholds either held constant for the best-case scenario soil class or dependent on the QCSI value. All the maps were obtained using the depth to bedrock data and were filtered.

sequently (except for the cross-sectional angle threshold of $1: 21)$ never above the corresponding fixed threshold for neither of the skill scores. The QCSI information thus does not appear to improve results.
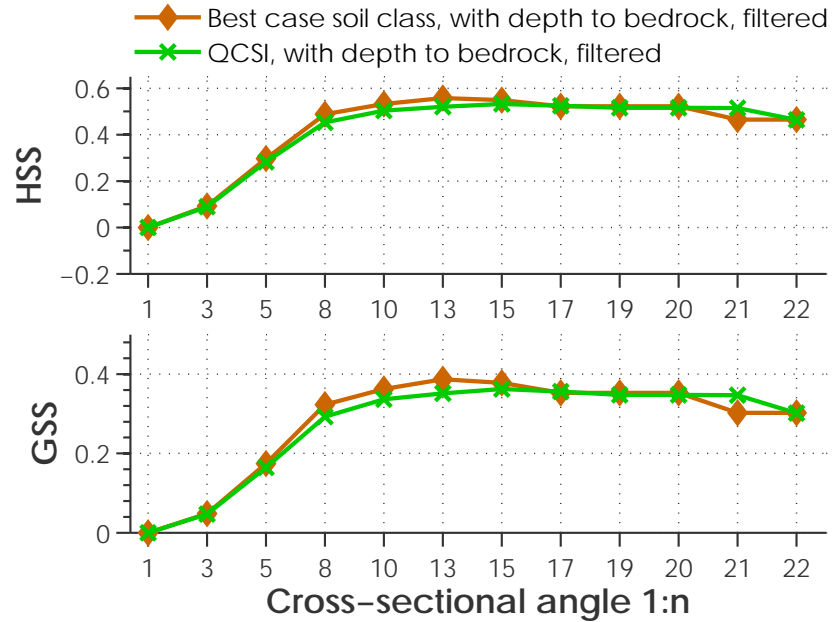

Figure 10. Heidke skill score and Gilbert skill score of the areas prone to landslides obtained with cross-sectional angle thresholds either held constant for the best-case soil class or dependent on the QCSI value. All the maps were obtained using the depth to bedrock data and were filtered. The effect of using QCSI-dependent crosssectional angle thresholds is shown for several values of the crosssectional angle threshold (i.e., from $1: 1$ to $1: 22$ ). Both skill scores show that the QCSI information is not improving the results, particularly in the $1: 8$ to $1: 13$ cross-sectional angle interval.

\section{Discussion and conclusions}

By using several methods to validate and compare the modeling results from running the algorithm with several settings and different filters, we have gained some insight into the performance of the algorithm and how to filter the resulting maps. In general, our results of the validation show that the algorithm has very good performance in spite of the relatively simple method (i.e., the method only needs two main data sources: a digital elevation model and a map of classified soil deposits). The filtering procedure, wherein some areas initially classified as prone to landslides are removed, is a very important step for increasing the overall performance and reducing map artifacts. However, no clear improvement is seen for high cross-sectional angles $(1: 1$ through $1: 5)$. At steep cross-sectional angles the areas classified as prone to landslides are often discontinuous, and this increases the risk that they are erroneously discarded by the filtering. Also, it should be noted that as the filter parameters were optimized with a cross-sectional angle threshold of $1: 10$, they may not be optimal for high cross-sectional angle thresholds. With all of this in mind, the only drawback of the filtering procedure is that it will slightly decrease the detection of areas correctly classified as prone to landslides.

Our results show that the inclusion of the depth to bedrock data does not significantly decrease the areas incorrectly identified as unstable and that the increased performance is not as significant as the increase of model performance obtained with filtering. We believe that there are two reasons 
for this: (1) the output of the models is very sensitive to changes in the cross-sectional angle thresholds, meaning the performance improvements gained from including the depth to bedrock data are hidden until very low angles are considered; (2) the resolution (cell size) of the depth to bedrock map is $50 \mathrm{~m}$ meaning that it gives only a rough idea of the bedrock surface. We believe that if the analysis were performed with a depth to bedrock map at the same resolution as the DEM, the effect of the bedrock data would be more evident, which may be the case if drilling or detailed geophysical investigations were done in an area of particular interest.

Surprisingly, the use of the QCSI-dependent crosssectional angle thresholds did not improve model performance. Since we found a relationship between the QCSI and the cross-sectional angle, we expected to obtain better performance by using the QCSI-dependent cross-sectional angle thresholds, especially when the validation was done by comparing the results of the algorithm with the landslide scarp maps. We propose two possible explanations for this: (1) the resolution of the QCSI map allows the establishment of a relationship between the QCSI values and the crosssectional angles extracted from the landslide scarps, but it is not high enough to provide optimal results on the resolution used in the performed analysis, and (2) the advantage of removing false positive detection via the QCSI-dependent cross-sectional angle thresholds may be more evident in areas with low frequency of landslides.

Our results show that the optimal cross-sectional angle thresholds are between $1: 8 / 1: 10$ and $1: 13 / 1: 15$, with the maximum performance reached at $1: 13$ in most of the cases. This suggests that $1: 13$, rather than the $1: 10$ used generally in Sweden, should be used as cross-sectional angle threshold in the overview mapping of areas prone to landslides.

In our test area around the Göta River there are significant quick clay deposits and many well-documented landslides. Despite the different geological and climate areas in Sweden, we believe that conclusions based on data from this area will be generally applicable to quick clay areas throughout the country, and even in other countries where quick clay may be present. In order to proceed with the assessment of landslide susceptibility at national level, our recommendations are (1) to use our algorithm as it is relatively fast and memory efficient, and allows the inclusion other information (e.g., depth to bedrock), (2) to post-filter the obtained maps to automatically remove areas falsely identified as prone to landslides and to use statistical measurements to optimize the filtering parameters, and (3) to perform the analysis using the currently available depth to bedrock map as it can slightly improve the reliability of results. However, a map of the depth to bedrock with a higher resolution $(<50 \mathrm{~m}$ pixel size) is desirable, and (4) to further examine the use of the QCSI-dependent cross-sectional angle thresholds and evaluate the effect of these thresholds in areas with a lower frequency of landslides.
Acknowledgements. This work was financially supported by the Swedish Civil Contingencies Agency (MSB), contract 2010-2787. We would like to thank the Geological Survey of Sweden (SGU) for providing data and comments on our work. We really appreciate the help of Roland Roberts and Jean-Marc Mayotte in reviewing the language.

Edited by: F. Catani

Reviewed by: P. Quinn and one anonymous referee

\section{References}

AA.VV.: Landslide Risks in the Göta River Valley in a Changing Climate, Swedish Geotechnical Institute, Linköping, Sweden, 164 pp., 2012.

Andersson-Sköld, Y., Torrance, J. K., Lind, B., Odén, K., Stevens, R. L., and Rankka, K.: Quick clay - a case study of chemical perspective in southwest Sweden, Eng. Geol., 82, 107-118, 2005.

Bell, R., Petschko, H., Bauer, C., Glade, T., Granica, K., Heiss, G., Leopold, P., Pomaroli, G., Proske, H., and Schweigl, J.: Implementation of landslide susceptibility maps in Lower Austria as part of risk governance, EGU General Assembly, Vienna, Austria, 27 April-2 May 2013, EGU2013-10204, 2013.

Berggren, B., Fallsvik, J., and Viberg, L.: Mapping and evaluation of landslide risk in Sweden, in: Landslides, edited by: Bell, D. H., Balkema, Rotterdam, 873-878, 1991.

Berggren, B., Alén, C., Bengtsson, P.-E., and Falemo, S.: Metodbeskrivning sannolikhet för skred: kvantitativ beräkningsmodell (Description of the Method for Landslide Probability: a Quantitative Calculation), Swedish Geotechnical Institute, Linköping, Sweden, 142 ,pp., 2011.

Chung, C.-J. C. and Frabbri, A. G.: Validation of spatial prediction models for landslide hazard mapping, Nat. Hazards, 30, 451472, 2003.

Daniels, J. and Thunholm, B.: Rikstäckande jorddjupsmodell, Sverige (Soil Depth Model, Sweden), Geologiska Undersökning, Uppsala, Sweden, 14 pp., 2014.

Demers, D., Leroueil, S., and d'Astous, J.: Investigation of a landslide in Maskinongé, Québec, Can. Geotech. J., 36, 1001-1014, 1999.

Erener, A., Lacasse, S., and Kaynia, A. M.: Landslide hazard mapping by using GIS in the Lilla Edet province of Sweden, in: Proceedings of the 28th Asian Conference on Remote Sensing, Kuala Lumpur, 12-16 November 2007, 67-73, 2007.

Gilbert, G. F.: Finley's tornado predictions, Am. Meteorol. J., 1, 166-172, 1884.

Guzzetti, F., Reichenbach, P., Ardizzone, F., Cardinali, M., and Galli, M.: Estimating the quality of landslide susceptibility models, Geomorphology, 81, 166-184, 2006.

Hågeryd, A.-C., Viberg, L., and Lind, B.: Frekvens av skred i Sverige (Landslide Frequency in Sweden), Swedish Geotechnical Institute, Linköping, Sweden, Varia 583, 16 pp., 2007.

Hågeryd, A.-C., Viberg, L., and Lind, B.: Frekvens av skred i Sverige (Landslide Frequency in Sweden), Swedish Geotechnical Institute, Linköping, Sweden, Varia 583, 16 pp., 2007. 
Heidke, P.: Berechnung des Erfolges und der Güte der Windstärkevorhersagen im Sturmwarnungdienst (Calculation of the success and goodness of strong wind forecasts in the storm warning service), Geogr. Ann., 8, 301-349, 1926.

Høst, J., Derron, M.-H., and Sletten, K.: Digital rock-fall and snow avalanche susceptibility mapping of Norway, in: Landslide Science and Practice, edited by: Margottini, C., Canuti, P., and Sassa, K., Springer, Berlin, Heidelberg, 313-319, 2013.

Karlsson, R. and Hansbo, S.: Soil Classification and Identification, Document D8:1989, Byggforskningsrådet, Stockholm, 1989.

Larsson, R., Bengtsson, P.-E., and Edstam, T.: Vägbyggande med hänsyn till omgivningens stabilitet (Road Construction with Respect to Slope Stability), Vägverket Region Väst Dnr AL90 B 2007:27435, Swedish Geotechnical Institute slutrapport, Linköping, 32 pp., 2008.

LESSLOSS: Application of Landslides Zonation Techniques to Study Areas, Sixth Framework Programme, Priority 1.1.6.3: Global Change and Ecosystems, D-94, 275 pp., 2007.

Lindberg, F., Olvmo, M., and Bergdahl, K.: Mapping areas of potential slope failures in cohesive soils using a shadow-casting algorithm - a case study from SW Sweden, Comput. Geotech., 38, 791-799, doi:10.1016/j.compgeo.2011.05.003, 2011.

Lundqvist, J. and Wohlfarth, B.: Timing and east-west correlation of south Swedish ice marginal lines during the Late Weichselian, Quaternary Sci. Rev., 20, 1127-1148, 2001.

Lundström, K. and Andersson, M.: Hazard mapping of landslides, a comparison of three different overview mapping methods in finegrained soils, in: Proceedings of the 4th Canadian Conference on Geohazards: from Causes to Management, Presse de l'Université Laval, Quebec, 2008.

Lysell, G.: Ny Nationell Höjdmodell, NNH, Lantmäteriets Nyhetsbrev, 1, Gävle, 2 pp., 2013.

Mitchell, R. J. and Markel, A. R.: Flowsliding in sensitive soils, Can. Geotech. J., 11, 11-31, 1974.

Oh, H. J. and Pradhan, B.: Applican of a neuro-fuzzy model to landslide-susceptibility mapping for shallow landslides in a tropical hilly area, Comput. Geosci., 37, 1264-1276, 2011.

Osterman, J.: Studies on the properties and formation of quick clays, Clay. Clay Miner., 12, 87-108, 1963.
Påsse, T.: Havsstrandens nivå förändringar i norra Halland under Holocen tid (Seashore Level Changes in Northern Halland During the holocene), $\mathrm{PhD}$ thesis, Geological Department, Chalmers Technical University, Göteborg, Sweden, 174 pp., 1983.

Persson, M. A., Stevens, R. L., and Lemoine, Å.: Spatial quickclay predictions using multi-criteria evaluation in SW Sweden, Landslides, 11, 263-279, 2014.

Quinn, P. E.: Large Landslides in Sensitive Clay in Eastern Canada and the Associated Hazard and Risk to Linear Infrastructure, $\mathrm{PhD}$ thesis, Queen's University, Kingston, Canada, 437 pp., 2009.

Rankka, K., Andersson-Sköl, Y., Hulten, C., Larsson, R., Leroux, V., and Dahlin, T.: Quick Clay in Sweden, Swedish Geotechnical Institute, Linköping, Sweden, Rep. 65, 148 pp., 2004.

Schaefer, J. T.: The critical success index as an indicator of warning skill, Weather Forecast., 5, 570-575, 1990.

Stevens, R. L.: Proximal and distal glacimarine deposits in southwestern Sweden: contrasts in sedimentation, Geological Society, London, Special Publications 53, 307-316, 1990.

Svedhage, K.: Stratigraphic indications of a Pleistocene/Holocene transgression in the Göta ÁUlv river valley, SW Sweden, Boreas, 14, 87-95, 1985.

Torrance, J. K.: Towards a general model of quick clay development, Sedimentology, 30, 547-555, 1983.

Torrance, J. K.: Chemistry, sensitivity and quick-clay landslide amelioration, in: Landslides in Sensitive Clays - from Geosciences to Risk Management, edited by: L'Heureux, J.-S., Locat, A., Leroueil, S., Demers, D., and Locat, J., Springer, Dordrecht, 15-24, 2014.

Trigila, A., Frattini, P., Casagli, N., Catani, F., Crosta, G., Esposito, C., Iadanza, C., Lagomarsino, D., Mugnozza, G. S., Segoni, S., Spizzichino, D., Tofani, V., and Lari, S.: Landslide susceptibility mapping at national scale: the Italian case study, in: Landslide Science and Practice, edited by: Margottini, C., Canuti, P., and Sassa, K., Springer, Berlin, Heidelberg, 287-295, 2013.

Tryggvason, A., Melchiorre, C., and Johansson, K.: A fast and efficient computer algorithm for landslide prerequisites mapping based on detailed soil and topographical information, Comput. Geosci., 75, 88-85, 2015. 